\title{
DEUS SIVE POPULUS \\ JOSEPH DE MAISTRE, JEAN-JACQUES ROUSSEAU Y LA CUESTIÓN DE LA SOBERANÍA ${ }^{1}$
}

\author{
JOSEPH DE MAISTRE, JEAN-JACQUES ROUSSEAU AND THE QUES- \\ TION OF SOVEREIGNTY
}

\author{
Michaël Rabier ${ }^{2}$ \\ Instituto Hannah Arendt, Universidad Paris-Est, (Francia).
}

Recibido: 24-05-2013

Aceptado: 25-07-2013

Resumen: La filosofía política de Joseph de Maistre se ha construido en contra de los planteamientos contractualistas de Jean-Jacques Rousseau. Sin embargo, más allá de sus divergencias sobre el origen de la soberanía - divino para uno, popular para el otro - se pueden constatar ciertas convergencias entre las concepciones del uno y del otro en torno a su naturaleza. Aquí se revelan tal vez dos figuras adversas de una misma noción en la medida que el poder obedece siempre a un principio trascendente o a un "concepto metafísico" (Jouvenel), secularizado o no, que lo subordina y del cual extrae su legitimidad. Palabras-clave: derecho divino, soberanía divina, soberanía popular, voluntad general, contractualismo.

\begin{abstract}
The political philosophy of Joseph de Maistre has been built against the contractarian approach of Jean-Jacques Rousseau. However, beyond their differences over the origin of the sovereignty - divine for one, popular for the other - we can find some convergences between the ideas of the one and the other about its nature. Here are perhaps two adverse figures of a same notion insofar as power always obey a transcendent principle or "metaphysical concept" (Jouvenel), secular or not, that subordinates him and which derives its legitimacy.
\end{abstract}

Key-words: divine right, divine sovereignty, popular sovereignty, general will, contractualism.

[1] Traducción: Isidro Vanegas.

[2] (michael.rabier@gmail.com). 
En muchos aspectos, la obra de Joseph de Maistre (1753-1821) es indisociable de los acontecimientos políticos que la vieron nacer. Sin la Revolución y sus consecuencias, el gentilhombre saboyano habría proseguido tranquilamente su prometedora carrera de magistrado en Chambéry al servicio de la corona de Piamonte-Cerdeña. Seguramente también se habría consagrado a la escritura y a la reflexión sobre las instituciones monárquicas - como lo testimonian sus preocupaciones anteriores a $1789^{3}$ - aunque de una manera menos polémica y con un objetivo meramente reformador. Opuesto a la autocracia de Carlos-Manuel III, él deseaba rehabilitar los contrapoderes tradicionales. Sin embargo, la historia o la providencia - para emplear un término eminentemente maistriano- decidió lo contrario. Así, 1793 señala el momento en que su existencia cambia. El Terror hace su entrada en Saboya, que él abandona ante la llegada de las tropas revolucionarias, siendo además este año el de la decapitación del Rey de Francia. En el abismo dejado por la cabeza cortada de Luis XVI es que Maistre, por lo tanto, va a asomarse con el fin de comprender el fenómeno revolucionario y refutar sus principios. Para él se trata de "pensar la revolución" según la fórmula que empleará François Furet.

Exiliado en Lausana, ante el desastre a la vez personal y político causado por el acceso de los Jacobinos al poder, Maistre decide lanzarse al combate intelectual contra la Revolución francesa e inaugura así, entre Edmund Burke (Reflexiones sobre la Revolución de Francia, 1790) y Nicolás de Bonald (Teoría del poder político y religioso, 1796) el gesto contrarrevolucionario a nivel literario, siempre llevando su pensamiento en la misma dirección: la refutación de la filosofía de las Luces y de su supuesto referente intelectual Jean-Jacques Rousseau.

En efecto, Joseph de Maistre comprendió rápidamente cuál era el principio que movía la Revolución: la teoría de la soberanía del pueblo4 . Su Quinta carta de un monarquista saboyano a sus compatriotas, redactada desde enero de 1794 pero nunca publicada como tal —aunque le servirá de boceto para $L a$ soberanía del pueblo y las Consideraciones sobre Francia (1797) —, menos circunstancial que las anteriores, la dedica a una refutación del origen popular de la soberanía. Para él, son las ideas de Rousseau las que es preciso atacar pues fue este quien sentó las bases teóricas de la Revolución, según una interpretación que todos los contrarrevolucionarios luego de él retomarán. Con todo, podemos también constatar ciertas convergencias, y esto debido a que no puede haber confrontación sin diálogo, y porque a pesar de ella ambos son hijos de su

[3] En particular sus discursos de regreso al senado de Chambéry: en 1777, el Discurso sobre la virtud, y en 1784, sobre el Carácter exterior del magistrado. También su primer escrito político, el Elogio de Víctor-Amadeo III (1775), la Memoria al duque de Brunswick (1782) y la Memoria sobre la venalidad de los cargos (1788).

[4] Henri de Maistre apunta en su biografía (Joseph de Maistre, París, Perrin, 1990, p. 204) que sus registros de lectura indican la recurrencia del tema a partir de 1788.

THÉMATA. Revista de Filosofía, Nº49 enero-junio (2014) pp.: 293-315

doi: 10.12795/themata.2014.i49.16 
tiempo, críticos de su época - la del racionalismo de las Luces 5 -, herederos de los siglos anteriores y admiradores del pensamiento antiguo ${ }^{6}$. Convergencias entre las concepciones que los dos tenían no solamente en torno al papel de la religión o de dios en la fundación del Estado o de las instituciones como lo ha destacado muy bien recientemente Ronald Beiner ${ }^{7}$ sino también en torno a la naturaleza misma de la soberanía. En efecto, más allá de sus divergencias sobre su origen - divino para uno, popular para el otro-, en sus filosofías políticas se revelan "dos figuras adversas de un mismo concepto de la soberanía", para reformar la fórmula de Jean-Yves Pranchère ${ }^{8}$, dos figuras adversas que no han sido confrontadas en detalle hasta entonces.

\section{Origen de la soberanía: Deus sive populus}

Maistre se propone demostrar la inanidad de la teoría contractualista recogida y desarrollada por Rousseau ${ }^{9}$, y así criticar la idea de una constitución propiamente humana de la sociedad mediante la voluntad general. En el Discurso sobre el origen de la desigualdad entre los hombres, Rousseau había postulado la hipótesis de que existe un estado de naturaleza en el cual los hombres vivían sin sociabilidad, sentando luego, en el Contrato Social, las bases del establecimiento de la sociedad en un pacto que marca la entrada a la vida civil. De este modo, el poder proveniente de la voluntad general solo tiene su legitimidad en el pueblo, y la sociedad se ve creada por una decisión humana, puramente humana. Habiendo percibido el vínculo entre los dos principales escritos políticos de Rousseau, Maistre quiso por eso refutarlos

[5] Como lo observa con mucha razón Jean-Yves Pranchère: "Se puede sostener que la propia filosofía autoritaria de Maistre es ella misma el lugar de la inversión dialéctica de una corriente de las Luces; más concretamente, está permitido ver en ella la descendencia paradójica de dos pensadores a los que todo sin embargo separa: Descartes y Rousseau" ("Maistre dans la dialectique des Lumières", Cahiers de l'association internationale des études françaises, $\mathrm{n}^{\circ} 525,2000$, pp. 103-115). Graeme Garrard había también subrayado esta convergencia "anti-iluminista" de ambos, incluso el papel de precursor de Rousseau, in "Rousseau, Maistre, and the counterenlightenment", History of Political Thought, Volume 15, n 1, 1994, pp. 97-120. Convergencia que no parece haber visto Iván Dario Arango, sobre todo en cuanto al antirracionalismo de ambos, en el capítulo dedicado principalmente a la crítica maistriana de Rousseau. cf. Críticos y lectores de Rousseau, Mellellin, Editorial Universidad de Antioquia, 2006.

[6] Según Léo Strauss, el pensamiento de Rousseau manifiesta la primera "crisis del espíritu moderno" cuyo remedio buscará en un retorno a las ideas de los clásicos, en particular, las de "ciudad" y de "virtud" (véase Droit naturel et histoire, cap. VI, a).

[7] Cf. Ronald Beiner, "Maistre and Rousseau : Theocracy versus Civil Religion" in Civil Religion, A Dialogue in the History of Political Philosophy, Cambridge University Press, 2011, pp. 353-358.

[8] Cf. Dictionnaire Joseph de Maistre, artículo " Rousseau " in Euvres de Joseph de Maistre (Pierre Glaudes ed.), Paris, Robert Laffont, « Bouquins », 2007.

[9] Los desarrollos acerca de este tema pueden verse en Dérathé, R, Jean-Jacques Rousseau et la science politique de son temps, París, PUF, 1950 (reedición París, Vrin, 1995).

THÉMATA. Revista de Filosofía, Nº49 enero-junio (2014) pp.: 293-315

doi: 10.12795/themata.2014.i49.16 
en conjunto. Reafirmando la idea aristotélica de la naturaleza sociable del hombre y la idea cristiana de la naturaleza humana falible, él contradice el contractualismo usado para justificar el origen divino de la soberanía y de la sociedad. Según Rousseau, en efecto, el pacto social mediante el cual "cada uno de nosotros pone conjuntamente su persona y todo su poder bajo la suprema dirección de la voluntad general"10 es el que crea al soberano. Este "acto de asociación" es el acto fundador del cuerpo político, que toma por lo tanto colectivamente el nombre de "Pueblo". Su origen es, pues, popular. El soberano, aunque formado de los "particulares que lo componen"11, representa una realidad superior a la cual cada uno debe obedecer como si se obedeciera a sí mismo. De ahí la necesidad de una enajenación total previa, así como la famosa fórmula que mucho le será reprochada: "Cualquiera que se niegue a obedecer a la voluntad general será obligado por todo el cuerpo: lo que no significa otra cosa que se le forzará a ser libre"12.

Maistre diverge completamente de este punto de vista, pues para él no existe el paso de un estado natural a uno civil. "Fue Dios quien creó al hombre sociable, y puesto que él quiso la sociedad, quiso también la soberanía y las leyes sin las cuales no hay sociedad"13. Al contrario de la demostración rousseauniana de la cual él - y otros - mostrará su carácter de círculo vicioso y denunciará su aspecto sofístico, su lógica pretenderá una forma casi silogística: 1. Dios creó al hombre sociable (Premisa mayor). 2. Ahora bien, no hay sociedad sin soberanía (Premisa menor). 3. Por lo tanto, Dios creó la soberanía (Conclusión).

Pero si desde un punto de vista metafísico la soberanía emana de Dios porque él es el autor de todo excepto del mal, no es menos cierto que ella se manifiesta por la mediación de los hombres. En efecto, existiendo una delegación del poder, ella viene de arriba y no de abajo, como lo creen los defensores de la soberanía popular y Rousseau a la cabeza. Por eso Maistre puede declarar sin contradicción ni paradoja que la pregunta acerca de si la soberanía viene de Dios o de los hombres admite la respuesta de que las dos proposiciones pueden ser verdaderas, a condición de tomarlas en dos sentidos diferentes.

En un sentido superior y ontológico, la soberanía viene de Dios en tanto él es el creador. Sin embargo, en un sentido inferior y puramente "fenomenológico" el poder requiere un consentimiento humano. La soberanía se establece a partir de una obediencia consentida: "Es muy cierto, en un sentido inferior y burdo — precisa Maistre—, que la soberanía está fundada en el consentimiento

[10] Contrat social, Écrits politiques, Euvres complètes, T. III, Bibliothèque de la Pléiade, Paris, Gallimard, 1964, L. I, 6, p. 361.

[11] Ob. cit., L. I, 7. , p. 363.

[12] Ibid, p. 364.

[13] De la souveraineté du peuple, París, PUF, 1992, L. I., 1, p. 93.

THÉMATA. Revista de Filosofía, Nº49 enero-junio (2014) pp.: 293-315 doi: 10.12795/themata.2014.i49.16 
humano; ya que si un pueblo cualquiera acordara repentinamente no obedecer, la soberanía desaparecería, y es imposible imaginar el establecimiento de una soberanía sin un pueblo que consienta obedecer". Y añade con el fin de clarificar su observación: "Por lo tanto si los adversarios del origen divino de la soberanía quieren decir solamente eso [que todo poder reposa en un consentimiento humano], tienen razón, y sería harto inútil discutirlo. No habiendo Dios juzgado adecuado el empleo de instrumentos sobrenaturales para el establecimiento de los imperios, es seguro que todo debió haber sido hecho por los hombres. Pero decir que la soberanía no viene de Dios porque él se sirve de los hombres para establecerla, es decir que él no es creador del hombre porque todos tenemos un padre y una madre" 14 .

La argumentación maistriana sobre este punto es muy coherente, y en ella distingue dos niveles de interpretaciones, diferenciando lo divino de lo humano en cuanto a la soberanía ${ }^{15}$, pues sin negar el papel de la voluntad humana en su esfera de acción, confirma al mismo tiempo al autor divino en su creación. Nos hallamos aquí ante la distinción escolástica entre lo eminente y lo formal ${ }^{16}$. Así, la soberanía viene de Dios en un sentido eminente, puesto que es de este principio que extrae su realidad, su ser. En cambio, en el sentido formal, es decir, actual, efectivo, la soberanía viene de los hombres, ya que es mediante ellos que se establece en el mundo. Como siempre en Maistre, el hombre no es más que un instrumento, un mediador o mandatario de la voluntad divina. Es, para retomar su expresión, un "agente pasivo"17. He aquí lo relativo al argumento ontológico tendiente a probar el origen divino de la soberanía. Veamos ahora lo que se podría llamar el argumento sociológico.

La otra razón por la cual la soberanía no podría provenir del pueblo, es que sin ella, simplemente no hay pueblo. En efecto, se constata una anterioridad, si no cronológica, al menos jerárquica entre la soberanía y el pueblo o la sociedad, ya que para Maistre los términos son equivalentes. Así lo señala en la Quinta carta a un monarquista saboyano, que le sirvió de esbozo para su estudio sobre la soberanía: "Esta palabra pueblo es una expresión relativa que solo tiene sentido en su relación con la de Soberano". Sola, no significa nada,

[14] Ibid., pp. 92-93.

[15] Ibid., p. 94: "No vengo en absoluto a decirles que la soberanía viene de Dios o de los hombres; solo examinemos juntos lo que hay de divino y de humano en la soberanía".

[16] Por otro lado, Maistre emplea el término (ob. cit.) “... y los partidarios del sistema contrario no pueden negar a su vez que Dios no sea por excelencia y de una manera eminente el autor de estos gobiernos "(nosotros somos quienes subrayamos).

[17] Ibid., L. I, 12, p. 167, nota 2: "La generación es un misterio impenetrable: el hombre no es más que un agente pasivo, un instrumento ciego entre las manos de un obrero oculto que no dice su secreto. La influencia del hombre en la formación de los gobiernos es aproximadamente la misma".

THÉMATA. Revista de Filosofía, Nº 49 enero-junio (2014) pp.: 293-315

doi: 10.12795/themata.2014.i49.16 
como la idea de hijo no puede subsistir separada de la de padre"18.

Hay allí una relación de generación entre la soberanía y el pueblo, puesto que sin poder común, el "pueblo" queda reducido a un estado atomizado, de dispersión y aislamiento de las partes. Tampoco habría, por otra parte, hombres en sentido estricto, seres sociales, puesto que la sociedad no está constituida. Es la soberanía quien crea un pueblo en tanto que comunidad social, de la misma manera que la paternidad engendra la filiación. Maistre utiliza otra analogía, extraída esta vez del reino animal, para expresar esta idea: "Es tan imposible figurarse una sociedad humana, un pueblo sin soberano como una colmena y un enjambre sin reina, pues el enjambre, en virtud de las leyes eternas de la naturaleza, existe así o no existe". La colmena representa el tipo ejemplar de sociedad jerarquizada que sólo existe a través de la reina, por la cual cada abeja ejerce su función. Ahora bien, solo existe sociedad humana en la medida que se organiza a partir de un principio superior que es el poder soberano. Pero no es menos evidente que para que se establezca un poder se necesitan hombres que lo hagan necesario. El hombre aislado no es un hombre así como el poder solo no sería soberano. Por eso se constata la colateralidad o la interdependencia de estas dos entidades en virtud de las leyes de la naturaleza social. Incluso si es la soberanía quien hace al pueblo, ella no puede existir como tal sin aquél, así como no se puede llamar "padre" sino al que tiene hijos, y viceversa.

Este argumento permite a Maistre bosquejar una génesis de la sociedad a partir de la familia como célula primaria, el cual recuerda el análisis aristotélico de La Política y será retomado por los trabajos históricos posteriores de Fustel de Coulanges sobre la formación de la ciudad griega ${ }^{19}$. Para Maistre, en efecto, la primera imagen del poder se encuentra en el pater familias, autoridad masculina que gobierna la familia. Después, habiendo las familias venido a agregarse, les resulta necesario recurrir a un poder superior, soberano, y reconocer leyes comunes. Solamente entonces forman un pueblo: "El primer hombre fue rey de sus hijos; cada familia aislada fue gobernada de la misma manera. Pero en cuanto las familias se relacionaron, fue necesario un soberano, y este soberano las hizo pueblo dándoles leyes, puesto que solo hay sociedad mediante el soberano"20.

Por eso la constitución social de la humanidad implica una superioridad jerárquica de la soberanía, una subordinación del pueblo, y no un salto de un

[18] Véase Revue des études maistriennes, $\mathrm{n}^{\circ}$ 4, p. 49.

[19] Véase. La cité antique, L. III, cap. 3, en el cual muestra cómo la ciudad se ha formado por agregación progresiva de la familia a la fratria y a la tribu, para terminar por constituir una ciudad. Bertrand de Jouvenel observa también (Du pouvoir, Paris, Pluriel, 1998, L. II, cap. IV, p. 121 y sig.) que de Aristóteles a Bonald (y hasta Maurras, se podría añadir), todos los pensadores políticos "clásicos" reconocieron esta filiación.

[20] De la souveraineté du peuple, ob. cit., L. I, 3, pp. 104-105.

THÉMATA. Revista de Filosofía, Nº49 enero-junio (2014) pp.: 293-315

doi: 10.12795/themata.2014.i49.16 
estado a otro que se operaría por deliberación de los individuos. Aquí es la necesidad social la que sirve de prueba al origen divino de la soberanía. Es porque el hombre ha sido creado naturalmente sociable que la soberanía viene de Dios, puesto que no puede haber sociedad sin soberanía: "La palabra pueblo es un término relativo que no tiene sentido separado de la idea de soberanía, ya que la idea de pueblo concita la de una agregación alrededor de un centro común, y sin soberanía no puede haber conjunto ni unidad política. Es necesario, pues, apartar hacia los espacios imaginarios las ideas de escogencia y deliberación en cuanto hace a la fundación de la sociedad y de la soberanía. Esta operación es la obra inmediata de la naturaleza o, para decirlo mejor, de su autor"21.

Según Maistre, el truco filosófico del contractualismo fue abstraer y aislar un término - "la soberanía" - de otro - "el pueblo"-, ignorando de esta forma la relación de subordinación del segundo respecto al primero, para poder a continuación asignar imperceptiblemente la soberanía al pueblo. De esta manera se hace salir de abajo lo que había entrado por arriba, mediante una "jugarreta conceptual" haciendo de la soberanía popular un sofisma que él descompone de la siguiente forma en la Quinta carta de un monarquista saboyano: "Si por esta palabra de Pueblo se entiende, pues, un cierto número de hombres reunidos bajo las leyes de una soberanía cualquiera, la idea queda clara y la concibo perfectamente. Pero si se hace abstracción de un soberano separado del pueblo y se traspasa a este último la idea de la Soberanía, entonces ya no sé lo que es un Pueblo"22.

En efecto, ¿qué es un pueblo si no hay soberanía para constituirlo? Él no existe como tal sino a condición de ser gobernado, por lo tanto, de no ser poseedor de la soberanía. Que exista una interdependencia entre la soberanía y el pueblo eso no implica la existencia de una pertenencia de lo uno a lo otro. Al contrario, si necesariamente hay una subordinación del pueblo a la soberanía, en el otro sentido, hay una entera independencia de origen de la soberanía con relación al pueblo. Ya que, en la hipótesis opuesta, no se da ningún contenido al término pueblo puesto que no existe sino como sujeto de un poder común. Sin esta agregación no hay pueblo, y en consecuencia, menos aún soberanía de éste. La idea de soberanía del pueblo tal como lo concibe Rousseau resulta pues, a su modo de ver, una contradicción lógica y práctica: "El pueblo es soberano, se dice, y ¿de quién? —De sí mismo al parecer. El pueblo es pues súbdito. Aquí seguramente hay algún equívoco, si no un error, ya que el pueblo que manda no es el pueblo que obedece. Basta pues con enunciar la propuesta general: el pueblo es soberano, para sentir que esto necesita un comentario"23.

[21] Ibid., p. 105.

[22] Revue des études maistriennes, $\mathrm{n}^{\circ}$ 4, p. 49.

[23] De la souveraineté du peuple, ob. cit., L. I, 1, p. 91.

THÉMATA. Revista de Filosofía, Nº49 enero-junio (2014) pp.: 293-315 doi: 10.12795/themata.2014.i49.16 
¿Cómo entonces el pueblo podría ser a la vez agente y objeto del poder? ¿Mediante qué desdoblamiento mágico de su personalidad, el pueblo se encontraría mandando y obedeciendo simultánea e incluso alternativamente? Desde un punto de vista lógico, la definición del objeto excluye la del agente. Estos dos términos se oponen, expresan una relación de subordinación que desde un punto de vista práctico hace imposible su definición: el que manda no puede ser el que obedece.

Maistre, sin embargo, olvida, no logra pensarlo —o lo finge- la resolución de esta contradicción tal como Rousseau lo propone en el Contrato social ${ }^{24}$, al plantear la doble naturaleza del cuerpo político: objeto en tanto que obedece a la soberanía, y agente, ciudadano, en tanto que partícipe. "Cada individuo, precisa, contratando, por decirlo así, con sí mismo, se encuentra comprometido bajo una doble relación; a saber, como miembro del Soberano hacia los particulares, y como miembro del Estado hacia el Soberano"25. Ahora bien, en el sistema democrático moderno la resolución de esta contradicción se hace por medio de la representación. Se dirá así que el pueblo ejerce la soberanía a través de sus representantes, lo cual en Rousseau estaba vedado26: "Digo, pues, que la soberanía, no siendo sino el ejercicio de la voluntad general nunca puede enajenarse, y que el soberano, que es un ser colectivo, no puede ser representado sino por sí mismo; el poder muy bien puede transmitirse, no así la voluntad". Lo que entiende Rousseau por inalienabilidad es, pues, la imposibilidad de una delegación de soberanía en el orden legislativo —o sea representativo: "Hemos visto que la potencia legislativa pertenece al pueblo, y no puede pertenecer sino a él. Es fácil ver, al contrario, según los principios anteriormente establecidos, que la potencia ejecutiva no puede pertenecer a la generalidad como Legisladora o Soberana, porque esta potencia no consiste sino en actos particulares que no incumben en absoluto a la ley, ni, por lo tanto al Soberano, todos los actos del cual no pueden ser sino leyes"27. En el orden ejecutivo puede haber, entonces, un intermediario entre los súbditos y el Soberano, es decir, un gobierno. El ejecutivo, para Rousseau, no es más que un ejecutante que no hay que confundir con el soberano.

Pero según Maistre eso nos conduce a formular esta otra contradicción lógica: "el pueblo es un soberano que no puede ejercer la soberanía"28. Qué tipo

[24] Contrat social, ob. cit., L. I, 6.

[25] Ibid., L. I, 7., p. 362.

[26] Ibid., L. II, 1., p. 368.

[27] Ibid., L. III, 2, p. 395-396.

[28] De la souveraineté du peuple, ob. cit., L. I, 1, p. 92. Véase, también Cinquième lettre d'un royaliste savoisien..., p. 37: "Parece que la gran cuestión de la soberanía del pueblo se soluciona en cuanto se entienda. Basta con descartar los equívocos y con ligar a las palabras ideas precisas. No sólo la soberanía no viene del pueblo, sino que ella es la que hace al pueblo, y la idea de un pueblo no gobernado, deliberando para darse a un soberano es un absurdo que nunca

THÉMATA. Revista de Filosofía, Nº49 enero-junio (2014) pp.: 293-315

doi: 10.12795/themata.2014.i49.16 
de cualidad es esa, por lo tanto, de la que no se puede gozar? Nada. El pueblo en la democracia representativa no sería más que un soberano ficticio o virtual. Por otro lado, si lo fuera realmente por alternancia y mediante la representación, la aritmética misma permitiría concluir lo absurdo de esta propuesta, como lo observa Maistre con ironía: "Solo cada individuo masculino de este pueblo tiene el derecho de mandar durante un determinado tiempo: por ejemplo, si suponemos 25 millones de hombres en Francia y 700 diputados elegibles cada dos años, y si además supusiéramos que esos 25 millones de hombres fueran inmortales, y los diputados fueran nombrados uno tras otro, cada francés se convertiría en rey periódicamente cada tres mil quinientos años aproximadamente. Pero como en este espacio de tiempo no dejamos de morir de vez en cuando, y por otra parte los electores son amos de elegir como les plazca, la imaginación se asusta del número espantoso de reyes condenados a morir sin haber reinado"29.

Así pues, a la prueba lógica y práctica, él añade la prueba aritmética tendiente a mostrar la imposibilidad de la soberanía popular.

\section{Naturaleza de la soberanía: una, absoluta e inalienable}

Mientras que se oponen en torno a la cuestión del origen de la soberanía (Deus sive populus) - aunque quizá sólo de manera aparente, como lo veremos más adelante-, Maistre y Rousseau, herederos de Bodin, se acercan en cuanto a su definición. Entre los caracteres que permiten definir la naturaleza de la soberanía, Maistre retiene tres esenciales: su unidad, su carácter de absoluta y su inviolabilidad, traducción de la "inalienabilidad" rousseauniana.

Maistre afirma desde el principio del segundo libro De la soberanía del pueblo: "de cualquier manera que se defina y que se sitúe la soberanía, siempre es una, inviolable y absoluta"30. Es una, es decir, única. Eso significa que la decisión pertenece siempre a uno sólo en última instancia, no pudiendo ser dividida la autoridad política para poder reinar. Compartirla sería introducir un fermento de discordia en el gobierno de la sociedad. Un poder, para ser soberano, superior, debe colocarse como árbitro, sobre los particulares, no admitiéndose por lo tanto la posibilidad de que varios árbitros se disputen para saber cuál es el que detenta la autoridad suprema. De ahí que independientemente de la forma institucional que tome el poder — colocado sobre una o más cabezas-, la esencia de la soberanía sea siempre única por definición. Se trata casi de un perogrullada, que se podría formular parafraseando a Leibniz: una soberanía es una soberanía.

habría sido sostenido si el espíritu de partido hubiera tenido una conciencia. De ahí que vea usted a los propios partidarios de esta opinión quedan reducidos a contradecirse ellos mismos evidentemente: dicen que el pueblo es soberano y que no puede ejercer su soberanía: pero qué es entonces una propiedad de la que no se puede gozar?".

[29] Ibid.

[30] De la souveraineté du peuple, ob. cit., L. II, 1, p. 179.

THÉMATA. Revista de Filosofía, Nº 49 enero-junio (2014) pp.: 293-315 doi: 10.12795/themata.2014.i49.16 
En efecto, esta unicidad constituye su identidad a la vez teórica y práctica, la cual no puede enajenarse a riesgo de perder todo significado y toda eficiencia. Esta es la razón por la que Cardin Le Bret podía decir que la soberanía no es más divisible que el punto en geometría ${ }^{31}$. Así como un punto, si fuera divisible, dejaría de ser un punto, así mismo dividida la soberanía, dejaría de ser soberana. Se trata nada menos que de su naturaleza, de su definición analítica y a priori, diríase en términos kantianos: la unidad es el predicado contenido en el sujeto "soberanía". Maistre retoma a Rousseau en este punto: "Por la misma razón que la soberanía es inalienable, es indivisible. Ya que la voluntad es general o no lo es; es la del cuerpo del pueblo, o solamente de una parte. En el primer caso esta voluntad declarada es un acto de soberanía y hace la ley; en el segundo, sólo una voluntad particular, siendo a lo sumo un decreto" ${ }^{32}$. Según Maistre, concebir una soberanía divisible equivaldría a imaginar una quimera, asignándole una calidad que por esencia no puede tener. Rousseau hablaba "de un ser fantástico y formado por piezas recogidas"33 para describir ese soberano dividido - si no en su principio, al menos en su objeto-, en fuerza y voluntad, en ejecutivo y legislativo. Dividir la soberanía, sería enajenarla en el sentido literal, es decir, volverla otra cosa, modificar su naturaleza. Sería contradictorio en los términos que un poder que se califica de superior no pudiera ser el único capaz de disponer de su autoridad y se viera limitado en el orden temporal por otro poder. De modo que, en último término, éste vendría a ser el poder soberano. Como sea, es necesario remontarse siempre a un primer principio - en lo temporal como en lo espiritual-, el cual es único, sin lo cual nos condenamos a regresar ad infinitum. Un poder, constreñido por otro, deja de ser poder en el sentido verbal. Puede poseer contrapoderes, pero aún así sería necesario que existiera un poder, es decir, una única autoridad última y decisoria. Una soberanía compartida no es ya soberana pues eso implicaría una igualdad, la cual de por sí constituye una denegación de superioridad. El orden político debe basarse por lo tanto en una subordinación jerárquica, sin lo cual no hay orden ni concordia posibles. Esta es la razón por la que la limitación de la soberanía destruye la soberanía, puesto que la potencia que limita es siempre superior a la que es limitada. Maistre toma el ejemplo de la constitución inglesa con el fin de ilustrar su análisis.

Aunque en Inglaterra el poder se encuentra distribuido entre varias instancias - Rey, Cámara de los Pares, Cámara de los Comunes-, la soberanía no sigue siendo menos única y es el poder soberano en el cual debe residir la decisión, es decir el derecho a juzgar en último recurso. Así, Maistre constata que

[31] Véase De la Souveraineté du Roy (1632).

[32] Contrat social, L. II, 2, ob. cit., p. 369.

[33] Ibid.

THÉMATA. Revista de Filosofía, Nº49 enero-junio (2014) pp.: 293-315 doi: 10.12795/themata.2014.i49.16 
"la división de poderes de la que tanto se ha hablado, no toca nunca a la soberanía propiamente dicha que pertenece siempre a un hombre o a un cuerpo. En Inglaterra el verdadero soberano es el Rey. Un Inglés no es súbdito del parlamento, y por poderoso, por respetable que sea este famoso cuerpo, nadie se aviene a llamarlo soberano" ${ }^{34}$.

Si fuera de otra manera, si una de las cámaras o las dos se vieran investidas del derecho de juzgar y censurar al Rey, dejaría de ser posible el gobierno puesto que ninguno de los poderes tendría superioridad respecto al otro ${ }^{35}$. De hecho, según Maistre, el Parlamento inglés no es soberano puesto que está sometido a la autoridad del Rey, formando así en el mejor de los casos un contrapoder:

"Que se examinen todos los gobiernos posibles que tienen el derecho o la pretensión de llamarse libres: se verá que los poderes que parecen poseer una porción de la soberanía no son realmente más que contrapesos o moderadores que regulan y retrasan la marcha del verdadero soberano" 36 .

El principio mismo de la soberanía quiere que ella no se conjugue sino en singular. Ella, en sentido literal es absoluta, es decir, la única en detentar el poder. Como lo observa Maistre, quien una vez más retoma a Rousseau:

"La autoridad soberana no puede ni modificarse ni enajenarse: limitarla, es destruirla. Es absurdo y contradictorio que el Soberano reconozca a un superior; obligarse a obedecer a un amo es ponerse en plena libertad" ${ }^{37}$.

Es este por otra parte el origen de la hostilidad virulenta de Rousseau al sistema de representación:

"La soberanía no puede ser representada, por la misma razón que no puede ser enajenada; ella consiste esencialmente en la voluntad general, y la voluntad no se representa en absoluto: es la misma, o es otra; no hay punto medio" 38 .

\section{Como contraejemplo también cita el caso inglés:}

"El pueblo inglés piensa ser libre; se equivoca grandemente, sólo lo está durante la elección de los miembros del Parlamento; tan pronto estos son elegidos, es esclavo, no es nada" 39 .

[34] De la souveraineté du peuple, ob. cit., L. I, 1, p. 92.

[35] Ibid., p.180.

[36] Ibid., p. 182.

[37] Ibid., p. 180. Esta cita se encuentra en el Contrat Social, L. III, 16, pero Maistre omite a sabiendas su final ya que cambia el alcance que desea darle en su texto. Para Maistre se trata, en efecto, de justificar el carácter inviolable de la soberanía como delegación divina y no como voluntad del pueblo, que es el caso en Rousseau.

[38] Contrat social, ob. cit., L. III, 15, p. 429.

[39] Ibid., p. 430.

THÉMATA. Revista de Filosofía, Nº49 enero-junio (2014) pp.: 293-315

doi: 10.12795/themata.2014.i49.16 
En esta época, Rousseau sigue siendo un firme opositor del sistema de representación inglés, tan admirado por Montesquieu: "En cualquier caso, en el momento que un Pueblo se da Representantes, deja de ser libre" ${ }^{40}$. Incluso después de haber matizado un tanto esta posición radical, reitera esta crítica en sus Consideraciones sobre el gobierno de Polonia (1772): "no puedo sino admirar la negligencia, la incuria, y me atrevo a decir, la estupidez de Nación inglesa que después de haber armado a sus diputados con la suprema autoridad, no añade ningún freno para regular el uso que ellos podrán hacer durante los siete años enteros que dura su comisión" ${ }^{11}$. Como Rousseau, Maistre se hace el abogado del carácter inalienable y absoluto de la soberanía.

A este respecto conviene evitar un contrasentido terminológico. En efecto, el término absoluto, tan estropeado, tiende a evocar un poder arbitrario o incluso total, si no totalitario. Ese no es el caso, sin embargo, en estos dos autores. Dicho término deriva del latín absolutus (acabado, perfecto), que viene del verbo absolvere, el cual a su turno significa "absolver" en el lenguaje eclesiástico. Así, un poder absoluto es tenido por perfecto porque está excusado de las leyes humanas, es decir, porque se sitúa por encima de las leyes que regulan a los particulares. Eso no significa, sin embargo, que él esté por fuera de la ley. Si no está ligado por las leyes, tratándose aquí solamente de las leyes civiles, es porque él es quien las decreta y las hace respetar. La fórmula princeps solutus est legibus debe tomarse en este sentido y Maistre se propone hacerle justicia: "Se ha criticado mucho a los jurisconsultos romanos por haber dicho que el príncipe está por encima de las leyes (princeps est solutus legibus). Se habría sido más indulgente en consideración suya si se hubiera observado que ellos no se proponían hablar sino de las leyes civiles, o, para decirlo mejor, de los trámites que ellas establecen para los distintos actos civiles"42.

Se comprende que para Maistre no se trata, como algunos lo supusieron equivocadamente, de una defensa del absolutismo en el sentido de despotismo, sino de una definición de la naturaleza misma de la soberanía. Es necesario no olvidar su formación jurídica y su preocupación por la ley y por su respeto de ella como magistrado ${ }^{43}$. Él sabe muy bien que no hay libertad y paz civil sino en la obediencia a la ley, pero sabe también que la autoridad pública o política, si bien no puede gobernar sino mediante la ley, sin la cual se vuelve despótica, debe sin embargo ser independiente, a riesgo de no ser ya soberana.

[40] Ibid., p. 431.

[41] Considérations sur le gouvernement de Pologne, Écrits politiques, ob. cit., p. 979.

[42] De la souveraineté du peuple, ob. cit., p. 183.

[43] En una nota de lectura de agosto de 1788, escribe: "La libertad consiste en no obedecer más que a las Leyes, y la Soberanía consiste en poder hacer Leyes, y en poder hacerlas observar. Hay Libertad cuando se puede no obedecer sino a la Ley; hay despotismo cuando se gobierna por una voluntad no manifestada por la Ley; hay anarquía cuando no hay ningua voluntad que pueda regular el todo político" (citado por J.-L. Darcel en De la souveraineté du peuple, ob. cit., p. 48).

THÉMATA. Revista de Filosofía, Nº49 enero-junio (2014) pp.: 293-315

doi: 10.12795/themata.2014.i49.16 
Maistre se sitúa aquí en el linaje de los legistas medievales que afirmaban la plenitudo potestatis del soberano, único detentador de la prerrogativa legislativa, aunque ésta pudiera ser delegada a los magistrados del parlamento. Como Rousseau, que también hace del poder legislativo la matriz de la soberanía, él retoma la definición clásica dada por Bodin en el primero de sus Seis libros de la República. La naturaleza absoluta de la soberanía garantiza el carácter incondicional e independiente del poder con relación a otros. Es necesario que la soberanía disponga de esta única prerrogativa a fin de que no se someta a la obediencia a otra instancia. Bodin se explica de este modo:

"es necesario que aquéllos que son soberanos en ningún caso estén sujetos a las órdenes de otro y que puedan dar la ley a los súbditos y romper o destruir las leyes inútiles, para hacer otras: lo cual no puede hacer el que está sometido a las leyes, o a los que tienen mando sobre él. Esta es la razón por la que la ley dice que el Príncipe está excusado de la potencia de las leyes: y esta palabra de ley implica también en latín el comando del que tiene la soberanía”"44.

Este carácter absoluto no es, sin embargo, tanto normativo como constitutivo de la autoridad legislativa: no se puede a la vez ser agente y súbdito de la ley. Maistre como Rousseau se suman a Bodin en este punto preciso, el cual, por otra parte, justifica por sí solo el hecho de que todo poder sea absoluto, "no siendo posible que ningún poder detente una fuerza coercitiva sobre sí mismo, toda potencia censurable por otro poder está necesariamente sujeta a este poder, puesto que hace las leyes que la domina" ${ }^{45}$. Por definición, el poder no puede verse sometido a otro poder temporal, siendo él superior y por lo tanto inviolable. Pero eso no significa que pueda hacerlo todo impunemente. Ciertamente la soberanía posee el poder de hacer y deshacer la ley, pero este derecho no le es concedido sino en la medida que sea depositario de una prerrogativa divina. Si el soberano es el único amo en su reino, siempre lo es "después de Dios" Por ello, si bien se encuentra desligado de las leyes positivas, eso no implica de ninguna manera que pueda derogar las leyes naturales, de la costumbre y divina. Absoluto no significa pues arbitrario sino árbitro, es decir, independiente.

Rousseau también concibe la soberanía como absoluta, aunque más en un sentido horizontal que vertical:

"Así como la naturaleza da a cada hombre un poder absoluto sobre todos sus miembros, así el pacto social da al cuerpo político un poder absoluto sobre todos los suyos, y es este mismo poder el que, dirigido por la voluntad general porta, como lo dije, el nombre de soberanía”"

[44] Les six livres de la République, Paris, LGF, 1993, L. I, 8.

[45] De la souveraineté du peuple, ob. cit., L. II, 1, p. 180.

[46] Bodin observa que "no hay nada de más grande en la tierra después de Dios que los príncipes soberanos y que ellos son establecidos como Sus tenientes para comandar a los hombres" (ob. cit., L. I, 10).

[47] Contrat social, ob. cit., L. II, 4., p. 372.

THÉMATA. Revista de Filosofía, Nº49 enero-junio (2014) pp.: 293-315

doi: 10.12795/themata.2014.i49.16 
Es significativo que trate de este atributo en el capítulo consagrado a los "límites del poder soberano". Allí donde Maistre alegaba leyes divinas para contener la soberanía, Rousseau supone una "voluntad siempre justa". Mientras la voluntad es general, es decir, mientras aspira al bien común o tiende "a la utilidad pública", nadie puede sustraerse a su imperio.

"Convenimos, plantea Rousseau, en que todo lo que cada uno enajena mediante el pacto social, de su potencia, de sus bienes, de su libertad, es solamente la parte de todo aquello cuyo uso importa a la comunidad, pero es necesario convenir también en que el solo soberano es juez de esta importancia" ${ }^{48}$.

De ahí que "todos los servicios que un ciudadano puede prestar al Estado, él los ha de pagar tan pronto como el Soberano se los pide" ${ }^{49}$, en caso contrario el cuerpo político se disuelve inmediatamente.¿Por qué? Porque

\footnotetext{
"los compromisos que nos vinculan al cuerpo social no son obligatorios sino en razón de que son mutuos, y su naturaleza es tal que llenándolos no se puede trabajar para los otros sin trabajar también para sî”o.
}

Por la naturaleza del pacto, la reciprocidad y la igualdad preservan al ciudadano contra el abuso de la autoridad soberana. Rousseau, por lo tanto, sustituye la verticalidad trascendente de los teóricos del derecho divino por la horizontalidad inmanente, humana, de los pensadores del derecho natural. En efecto, “¿qué es un acto de soberanía”? se pregunta Rousseau:

"No es un acuerdo del superior con el inferior, sino un acuerdo del cuerpo con cada uno de sus miembros: acuerdo legítimo, porque tiene por base el contrato social, equitativo, porque es común a todos, útil, porque no puede tener otro objeto que el bien general, y sólido, porque tiene por garante la fuerza pública y el poder supremo" ${ }^{51}$.

Una vez más, dado su origen, obedecer al soberano en Rousseau, es obedecerse a sí mismo.

\section{Límites de la soberanía: el pueblo o el Papa}

Debe decirse entonces que este poder soberano, popular, horizontal, igualitario e inmanente no conoce en absoluto límites, que es, como lo criticaba Benjamin Constant, un poder sin bordes? Si por un lado Rousseau afirmó que "todos los servicios que un ciudadano puede prestar al Estado, él se los ha de pagar tan pronto como el soberano se los pide"; por otro lado, no se puede olvidar que "el soberano por su parte no puede cargar a los súbditos

[48] Ibid., p. 373

[49] Ibid.

[50] Ibid.

[51] Ibid. p. 374-375

THÉMATA. Revista de Filosofía, Nº49 enero-junio (2014) pp.: 293-315 doi: 10.12795/themata.2014.i49.16 
con ninguna cadena inútil a la comunidad; ni siquiera puede desearlo: ya que bajo la ley de la razón nada se hace sin causa, como tampoco sucede bajo la ley de naturaleza"52.

Si la soberanía en Rousseau no puede ser limitada desde el exterior a menos que deje de ser soberana, así tampoco el soberano puede permitírselo todo respecto a los ciudadanos. En efecto, el principio de igualdad constituye para Rousseau - aunque prefiera hablar de "principio de equidad", véase supra - la garantía de no abuso del poder en la medida que una voluntad no puede querer contra las voluntades. Su carácter general e igualitario - es decir, su reciprocidad - constituye su legitimidad. Rousseau prosigue en este mismo pasaje: "Los compromisos que nos ligan al cuerpo social sólo son obligatorios porque son mutuos, y su naturaleza es tal que llenándolos, él no puede trabajar para otro sin trabajar también para sí. Por qué la voluntad general siempre es justa, y por qué todos quieren constantemente la felicidad de cada uno de ellos, si no es porque no hay persona que no se apropie de esta palabra cada uno, y que no piense en sí mismo votando por todos? Lo que prueba que la igualdad de derecho y el concepto de justicia que ella produce deriva de la preferencia que cada uno se da y por lo tanto de la naturaleza del hombre, que la voluntad general para ser realmente tal debe serlo en su objeto así como en su esencia, que debe partir de todos para aplicarse a todos, y que pierde su rectitud natural cuando tiende a algún objeto individual y determinado; porque entonces juzgando lo que nos es extraño no tenemos ningún verdadero principio de equidad que nos guíe"53.

La garantía de autolimitación de la soberanía reside en el carácter general de la voluntad, no sólo en su esencia sino también en su objeto. Es decir que ella debe aplicarse a todos sin distinción (principio de equidad), pues de lo contrario introduciría un desequilibrio que abriría la vía a todo tipo de abuso de poder. La voluntad general no puede imponer a una categoría de ciudadanos obligaciones de las cuales otros estarían exentos. Aquí, es "el interés común" o "la utilidad pública" lo que importa y en estas fórmulas el segundo término pesa obviamente más que el primero. Así, en el pacto social todos se comprometen "bajo las mismas condiciones, y deben gozar todos de los mismos derechos" que hacen que "todo acto de soberanía, es decir, todo acto auténtico de voluntad general, obligue o favorezca igualmente a todos los Ciudadanos, de modo que el Soberano conoce solamente el cuerpo de la nación y no distingue a nadie de los que lo componen" ${ }^{4}$.

El poder soberano aparece, pues, según una paradoja que se encontrará también en Maistre, en forma de aporia, a la vez absoluto y limitado.

[52] Contrat social, ob. cit., L.II, 4., p. 373.

[53] Ibid.

[54] Ibid.

THÉMATA. Revista de Filosofía, Nº49 enero-junio (2014) pp.: 293-315 doi: 10.12795/themata.2014.i49.16 
Absoluto ya que, como lo vimos, no hay potencia que le sea superior, pues, de lo contrario, él no sería soberano. Pero limitado porque debe conservar su carácter general y recíproco. No puede "estatuir sobre un objeto individual" 55 puesto que es común a todos y orientado hacia el bien público. En este sentido es que Rousseau afirma paradójicamente que "el poder soberano, todo lo absoluto, todo lo sagrado, todo lo inviolable que es, no pasa ni puede pasar los límites de los acuerdos generales" ${ }^{\text {". }}$. Estos "acuerdos generales" que limitan a la soberanía y están determinados por el contrato no tienen nada que ver, como lo destacó Robert Dérathé ${ }^{7}$, con "leyes fundamentales" o una "constitución" según las concepciones de los juristas de la época - Burlamaqui y Pufendorf en particular-, contra quienes Rousseau se opondrá en la séptima de sus Cartas escritas desde la Montaña. En efecto, colocar la constitución, o una ley fundamental, sobre la autoridad soberana equivale a destruir la unidad del Estado. Si la constitución se sitúa por encima de la soberanía, ésta no quedará ni como una ni como absoluta sino condicionada, dividida y destruida por esto, según la alternativa: "ella puede todo o no es nada".

Por lo demás, el soberano no puede quedar ligado en el tiempo con una ley, así ella sea fundamental ${ }^{58}$, en virtud del carácter esencialmente discontinuo de la voluntad general. Lo que quiere en un momento, puede deshacerlo al momento siguiente. Rousseau insiste en esto en un pasaje del "manuscrito de Ginebra" suprimido luego en el Contrato, pero que devela bien el sentido de esta concepción transitoria de la voluntad: "aunque se hubiera encontrado por un momento el acuerdo de dos voluntades jamás se podría garantizar que este acuerdo durara aún al siguiente momento, y que no nacería oposición entre aquellas. El orden de las cosas humanas está sujeto a tantas revoluciones, y las maneras de pensar así como las maneras de ser, cambian con tanta facilidad que sería una temeridad afirmar que se querrá mañana lo que se quiere hoy, y si la voluntad general está menos sujeta a esta inconstancia, nada puede poner a cubierto la voluntad particular. Así, aunque el cuerpo social pudiera decir una vez, quiero ahora todo lo que quiere tal hombre, jamás podría decirlo hablando del mismo hombre, lo que él desea mañana, yo lo querría aún. Ahora bien, la voluntad general que debe dirigir al Estado no es la de un tiempo pasado, sino la del momento presente, y el verdadero carácter de la soberanía es que haya siempre acuerdo de tiempo, de lugar, de efecto, entre la dirección de la voluntad y el empleo de la fuerza pública, acuerdo con el cual no se puede contar tan pronto como otra voluntad, cualquiera que pueda ser dispone de esta

[55] Véase también Émile, L. V.

[56] Contrat social, ob. cit., L. II, 4., p. 375.

[57] Jean-Jacques Rousseau et la science politique de son temps, ob. cit., cap. V, III c.

[58] "No hay ni puede haber ningún tipo de ley fundamental para el cuerpo del pueblo, ni siquiera el contrato social" (Contrat social, ob. cit., L. I, 7, p. 362).

THÉMATA. Revista de Filosofía, Nº49 enero-junio (2014) pp.: 293-315

doi: 10.12795/themata.2014.i49.16 
fuerza"59. He aquí, pues, otro límite dado a la soberanía, no estructural (el principio de equidad) sino temporal en virtud de un principio que se podría llamar de actualidad o instantaneidad. La voluntad, que se expresa en el "momento presente", no puede estar ligada por la cadena del tiempo, más concretamente por el peso de un compromiso pretérito que se prolonga en el futuro. Para ser legítima, ella debe siempre ser actual o reactualizada permanentemente. Es la idea que Rousseau expresa claramente en esta primera versión del Contrato social:

"Además es contra la naturaleza de la voluntad, que no tiene ningún imperio sobre ella misma, comprometerse para el futuro [...] Pero la ley de hoy no debe ser un acto de la voluntad general de ayer sino de la de hoy, y estamos comprometidos a hacer, no lo que todos quisieron sino lo que todos queremos [...] De ahí que cuando la Ley habla a nombre del Pueblo, es en nombre del Pueblo de ahora y no de otrora"60.

Este aspecto de interinidad del compromiso, revocable a todo momento, que garantiza el acuerdo presente de la voluntad como límite temporal a la soberanía ${ }^{61}$ tiene por consecuencia la "forma provisional" que tomará la potencia ejecutiva, es decir, el gobierno. El ejecutivo no podría ser, en efecto, sino provisional "hasta que [el pueblo, es decir, la potencia legislativa] le agrade ordenar otra cosa"62. Principio de revocabilidad que solo puede evitar que la soberanía sobrepase sus prerrogativas. Es absoluta, una e inalienable, pero en el instante (véase nota 59) y para todos. Son estas las condiciones de la libertad, incluida la posibilidad de renunciar al contrato social mismo: "No pudiendo considerarse sino bajo la única y misma relación [el soberano] está en el caso de un particular contratante consigo mismo: de ahí que se ve cómo no hay ni puede haber ningún tipo de ley fundamental obligatoria para el cuerpo del pueblo, ni siquiera el contrato social"63.

Contrariamente a Rousseau, el problema de los límites de la soberanía se expresa en Maistre de manera más precisamente aporética: “¿Cómo limitar el poder soberano sin destruirlo?"64. Cómo puede plantearse esta cuestión paradójica cuando él mismo ha afirmado, retomando un juicio de Rousseau, que "la autoridad soberana no puede modificarse como tampoco enajenarse: limitarla,

[59] Contrat social, 1 ère version, Écrits politiques, ob. cit., L. I, 4, p. 295-296.

[60] Ibid., II, 2, p. 315-316.

[61] Un pasaje de los Fragments politiques (Écrits politiques, ob. cit., L. III, 11, p. 485) lo confirma aún más claramente: "Pero la soberanía que no es más que el ejercicio de la voluntad general es libre como ella y no está sometida a ninguna especie de compromiso. Cada acto de soberanía así como cada momento de su duración son absolutos, independientes del que precede y jamás el soberano actúa porque él lo quiso sino porque él lo quiere”.

[62] Contrat social, ob. cit., III, 18, p. 435.

[63] Ibid., I, 7., p. 362.

[64] Du Pape, in Oeuvres, T.II, Genève, Slatkine, 1980, L. II, 3, p. 171.

THÉMATA. Revista de Filosofía, Nº49 enero-junio (2014) pp.: 293-315

doi: 10.12795/themata.2014.i49.16 
es destruirla"65, y que un gobierno al cual se pueda resistir no existe ya como tal. Por sorprendente que eso parezca y sin que se contradiga, Maistre no piensa que el despotismo o el absolutismo - es decir, el riesgo de abuso de poderpueda verdaderamente existir. Hará en efecto esta observación importante en su texto Del Papa: "Cuando se habla de despotismo y de gobierno absoluto, raramente se sabe lo que se dice. No hay ningún gobierno que pueda todo. En virtud de una ley divina, hay siempre junto a toda soberanía una fuerza que le sirve de freno. Es una ley, es una costumbre, es la conciencia, es una tiara, es un puñal; pero siempre es algo"66.

Él encuentra en el mundo lo que se podría llamar un principio de compensación ${ }^{67}$, que supone que una potencia se encuentra siempre limitada de alguna manera: jurídica ("una ley"), tradicional y no escrita ("una costumbre", en la cual se pueden incluir las leyes fundamentales), interior y moral ("la conciencia”, aquélla que reconocía también su adversario Rousseau), religiosa ("una tiara"), o criminal ("un puñal"). Pese a este principio de autolimitación natural que permite protegerse contra la hybris del poder, Maistre va sin embargo a resaltar dos posibilidades de restricción de la soberanía, una interna y otra externa.

En efecto, aunque la propia potencia política pueda ser frenada in extremis eliminándose o siendo eliminada físicamente por otra, estas soluciones siguen siendo excepcionales. Se trata de la hipótesis más desfavorable, que no impide que el mal ya haya sido hecho. Esta es la razón por la que Maistre favorecerá la solución tradicional y religiosa mediante la "costumbre" y la "tiara", que permiten limitar la soberanía sin destruirla o que ella misma se destruya. En una perspectiva temporal en primer lugar, afirma un principio de limitación interno a partir de la idea de círculo de legitimidad.

Con el fin de resolver la paradoja de una soberanía a la vez absoluta y limitada, Maistre propone dos puntos de vista.

El primero, que ninguna soberanía es limitada en su definición, algo que precisa así: "cuando digo que ninguna soberanía es limitada, lo entiendo en su ejercicio legítimo, algo que es necesario subrayar cuidadosamente"68. Es legítimo lo que está fundado en derecho y en moral, siendo la legitimidad el reconocimiento de leyes (legitimus viene de lex, legis), sean escritas o no escritas. En este sentido, ella comprende más que la legalidad, que es la conformidad

[65] De la souveraineté du peuple, ob. cit., L. II, 1, p. 180.

[66] Du Pape, ob. cit., L. II, 9, p. 255.

[67] Él había mencionado este principio o "ley" de compensación en De la souveraineté du peuple: "Pero el autor de la naturaleza puso límites al abuso de la potencia: quiso que ella misma se destruyese en cuanto pasara esos límites naturales. Por todo lado él grabó esta ley; y, en el mundo físico así como en el mundo moral, nos rodea y nos habla a cada momento". De la souveraineté du peuple, ob. cit., L. II, 2, pp. 204 -205.

[68] Du Pape, ob. cit., L. II, 3, p. 178.

THÉMATA. Revista de Filosofía, Nº49 enero-junio (2014) pp.: 293-315

doi: 10.12795/themata.2014.i49.16 
solamente a las leyes positivas. Así, puede haber contradicción entre lo uno y lo otro cuando las leyes escritas se oponen a las leyes no escritas. Éstas circunscriben el ejercicio del poder y es por ello que se les puede dar el nombre de leyes. Además, no emanando de una instancia jurídica sino de la naturaleza misma de las cosas, constituyen el fundamento no escritural del ejercicio del poder, su círculo de legitimidad, fuera del cual la soberanía sobrepasa sus funciones y sus prerrogativas.

Esta es la razón por la que, y este el segundo punto de vista, se puede decir sin contradicción que toda soberanía está limitada en su práctica: "Ya que se puede decir igualmente, bajo dos puntos de vista diferentes, que toda soberanía es limitada, y que ninguna soberanía no está limitada. Está limitada en cuanto ninguna soberanía lo puede todo; no lo está en la medida que, en su círculo de legitimidad, trazado por las leyes fundamentales de cada país, es siempre y por todas partes absoluta, sin que nadie tenga el derecho a decirle que es injusta o equivocada. La legitimidad no consiste, pues, en conducirse de tal o cual manera en su círculo, sino en no salirse de ahí" ${ }^{69}$.

Una vez más, Maistre no se dedica ni a la moralidad propiamente dicha, ni a la legalidad, sino a la legitimidad. El círculo que dibuja es formal en el sentido que describe una estructura, una arquitectura política —una constitución, se diría hoy, aunque no escrita- que permite contener el poder pero no juzgarlo. Se trata de una definición de las atribuciones de la soberanía y no de un juicio de valor sobre su conducta. Maistre fue claro en torno a este principio, reafirmando con insistencia el carácter siempre limitado de la soberanía: "Lo que debe entenderse según la explicación que di más arriba [L. II, chap. III, $p$. 178]; es decir que no hay soberanía que, por la felicidad de los hombres, y por el suyo sobre todo, no sea limitada de alguna manera, pero que, en lo interior de esos límites, colocados como agrada a Dios, es siempre y por todas partes absoluta, y considerada como infalible. Y cuando hablo de ejercicio legítimo de la soberanía no entiendo en absoluto o no aludo en absoluto al ejercicio justo, lo que produciría una anfibología peligrosa, a menos que por esta última palabra se quiera indicar que todo lo que opera en su círculo es justo o considerado como tal: lo cual es la verdad. Por ello un tribunal supremo, mientras no se salga de sus atribuciones, es siempre justo; ya que es la misma cosa en la práctica ser infalible, o equivocarse sin falta" ${ }^{\prime}$.

No confundir legitimidad y justicia significa preservar el carácter infalible de la soberanía delimitando al mismo tiempo su ejercicio. La anfibología creada en el caso contrario sería peligrosa en la medida que pondría en entredicho la naturaleza absoluta de todo poder. La soberanía conserva sus atribuciones dentro del círculo descrito por las leyes fundamentales. Su espacio

[69] Ibid.

[70] Ibid., 10, nota 1, pp. 274 -275.

THÉMATA. Revista de Filosofía, Nº 49 enero-junio (2014) pp.: 293-315 doi: 10.12795/themata.2014.i49.16 
de legitimidad, es decir, su esfera de acción en sentido estricto, se sitúa en la línea trazada entre el punto central que representa y la circunferencia que la contiene, es decir las leyes que limitan su extensión ilegítima. Esta es la razón por la cual la legitimidad consiste en no salir de este círculo y no en conducirse de tal o cual manera en este círculo. Ella determina lo lícito y lo ilícito, pero no permite juzgar la acción del poder en su propio ámbito que, en la práctica, debe siempre considerarse como infalible, es decir, supuestamente justo; así como un tribunal en el orden judicial lo es en virtud de sus competencias.

Con todo, ¿qué pasaría si, no contenta con mantenerse en sus límites, la soberanía - el soberano - decide sobrepasarlos? ¿Cómo sería posible llamarla al orden en el momento que, mediante un acto ilegítimo, hubiera roto el círculo que ceñía su legitimidad? No recaemos en la aporia que aparecía en el problema del derecho de resistencia. Esto es, ¿quién ante esta transgresión, la sancionaría y en virtud de qué poder? Siendo únicamente interior la obligación instituida - las leyes fundamentales-, el tribunal sería una prolongación de la soberanía, es decir, a la vez juez y parte ${ }^{71}$. O más bien habría que recurrirse a una instancia exterior pero que pudiera ella misma ser reconocida como soberana sin destruir la soberanía. Estamos nuevamente ante una paradoja difícil de sostener. Sin embargo, el problema puede solucionarse con facilidad si no se pierde vista que la soberanía, según Maistre, es establecida por Dios. Así, el principio paulino supone que el poder temporal es una emanación de la potencia divina. Toda soberanía viene de Dios, siendo él el único que reina sobre el mundo. Ahora bien, hay otro poder derivado de él directamente: es el poder espiritual. En este sentido, sólo la soberanía pontificia puede satisfacer todos los criterios de resolución de la cuestión de la restricción del poder temporal.

Limitada, la soberanía no cesa por lo tanto de ser divina si, como lo sostiene Maistre, Dios lo ha querido así. Incluso es de su origen divino que esta limitación deriva su eficacia y su legitimidad. Sería, pues, un error de razonamiento creer que porque Dios es el autor de la soberanía, esta es incontrolable. $\mathrm{Al}$ contrario, y dado que solo él tiene el control de su creación, una restricción humana, demasiado humana de ella, conduciría a problemas insolubles. Esta es la razón por la que, según Maistre, "Dios sin duda es amo de crear una soberanía limitada en su principio mismo, o posteriormente, mediante un poder que él habría establecido en la época señalada por sus decretos; y bajo esta forma, sería divina" ${ }^{2}$.

Este poder establecido por Dios para limitar a posteriori la soberanía, es decir, luego que la hubo instalado, no modificaría su naturaleza puesto que no dejaría de ser una creación divina emanada de su voluntad. Se trata de la otra solución preconizada por Maistre, la de un principio de limitación externo.

[71] Du Pape, ob. cit., L. II, 2, p. 171.

[72] Du Pape, ob. cit., L. II, 3, pp. 179-180.

THÉMATA. Revista de Filosofía, Nº49 enero-junio (2014) pp.: 293-315 doi: 10.12795/themata.2014.i49.16 
Con relación al anterior — que, por otra parte, no invalida en ningún casotiene la ventaja, como las leyes fundamentales, de no cambiar la naturaleza de la soberanía, de conservar su esencia, es decir, su definición (una, absoluta e infalible). Esta limitación, sin embargo, añade el elemento de ser a la vez exterior al ámbito propio del poder temporal — la política - y del mismo origen que éste, o sea divino. Así, en una perspectiva espiritual, el Papa puede ejercer una restricción del poder temporal sin que la soberanía pierda sus atribuciones en su orden.

En efecto, la autoridad pontificia se impone a Maistre como la mejor respuesta a la cuestión de saber “¡a quién?” y “¿cómo?” es permitido resistir. La calidad principal del poder papal reside en el hecho de que, siendo espiritual, se sitúa en un plano distinto al poder secular, no quita a la autoridad suprema sus prerrogativas temporales y no puede promover la sedición de los gobernados. Por eso se coloca más allá de las vicisitudes de la vida política y no entra en competencia con sus actores: "La potencia pontificia, al contrario, es por esencia la menos propensa a los caprichos de la política. El que la ejerce además es siempre viejo, soltero y sacerdote; lo cual excluye las noventa y nueve centésimas partes de los errores y pasiones que perturban a los Estados. En fin, como está alejada, su potencia es de naturaleza diferente a la de los soberanos temporales, y nunca pide nada para él, se podría creer de manera bastante legítima que si bien no todos los inconvenientes son desvanecidos de esta manera, lo cual es imposible, quedarían tan pocos como es permitido esperarlo, siendo como es la naturaleza humana; lo que es para todo hombre sensato el punto de perfección"73.

Por definición y por condición, el papado reúne todas las cualidades que permiten limitar los inconvenientes del derecho de resistencia. Es, pues, in ordine ad spiritualia que el poder pontificio puede intervenir en la vida política, eventualmente juzgar a los príncipes -incluso excomulgarlos-y desligar a los súbditos de su juramento de fidelidad, pero siempre por excepción y por vía de intervención especial. Entendamos, la superioridad del Papa y la competencia que ella implica en materia de soberanía sólo se refiere al fin espiritual, aunque ésta pueda tener consecuencias temporales. Maistre es, pues, favorable a la separación de los poderes, en un sentido diferente sin embargo de Montesquieu: el poder temporal de un lado, el poder espiritual del otro. Él es un convencido de esta concepción equilibrada de la sociedad medieval basada en dos pilares: la corona y la tiara ${ }^{74}$. Por lo tanto nunca predicará una confusión de los poderes propia de lo que se llama teocracia o "agustinismo político" sino que, al contrario, criticará severamente el galicanismo por haber querido

[73] Ibid., p. 183.

[74] Ibid., 9, p. 256: "Ahora bien, la autoridad de los Papas fue la potencia escogida y constituida, en la Edad Media, para equilibrar la soberanía temporal, y hacerla soportable a los hombres".

THÉMATA. Revista de Filosofía, Nº49 enero-junio (2014) pp.: 293-315

doi: 10.12795/themata.2014.i49.16 
sustraer lo temporal a la subordinación de lo espiritual. Interesa a Maistre que exista esta potencia toda espiritual como autoridad exterior al poder temporal.

Así, aunque aparentemente opuestos, los dos sistemas, el de derecho divino y el de la soberanía popular, están en realidad emparentados si se considera, con Bertrand de Jouvenel, que tras el concepto jurídico de soberanía existe un concepto metafísico, esto es, que "una Voluntad suprema ordena y rige la comunidad humana, una Voluntad buena por naturaleza y a la cual sería culpable oponerse, sea Voluntad Divina o Voluntad General"75. Una interpretación que lo llevará a afirmar que "al salir de las manos de Rousseau la teoría de la Soberanía Popular ofrece un paralelismo harto sorprendente con la teoría medieval de la Soberanía Divina". "Lo uno y lo otro, precisa, admiten un derecho ilimitado de mandato, pero que no es inherente a los gobiernos. Este derecho pertenece a una potencia superior - Dios o el Pueblo- impedida por su naturaleza para ejercerlo por sí misma. Y que por lo tanto debe conceder un mandato al Poder efectivo"76.

En efecto, lo uno y lo otro no hace a los gobernantes los detentadores de la soberanía sino solamente sus mandatarios: esto último pertenece propiamente a Dios o al Pueblo, contenido por normas, Voluntad Divina o Voluntad General. Hasta se podría añadir que Rousseau, heredero del concepto medieval a pesar de sí mismo, operó una especie de transferencia de soberanía de Dios al Pueblo, como lo ha postulado Carl Schmitt en su Teología política I al decir que "todos los conceptos de la moderna teoría del estado son conceptos teológicos secularizados"77.

En definitiva, cualquiera sea el origen de la soberanía, Dios o el Pueblo, el poder obedece siempre a un principio trascendente o a un "concepto metafísico" (Jouvenel), secularizado o no, que lo subordina y del cual extrae su legitimidad. Con Maistre y Rousseau, más allá de su divergencia, estamos enfrentados por lo tanto, más que a dos "figuras adversas" (Jean-Yves Pranchère) de la soberanía, a dos facetas de ese concepto, su derecho y su revés, que testimonian una constante subterránea a través del tiempo más allá de sus metamorfosis.

[75] Du pouvoir, ob. cit., L. I, cap. 2, p. 58.

[76] Ibid, p. 78.

[77] Carl Schmitt, Teología política I, en Carl Schmitt, Téologo de la política (prólogo y selección de textos de Héctor Orestres Aguilar), México, Fondo de Cultura Económica, 2001, p. 43. YvesCharles Zarka también ha subrayado el aspecto no solamente político sino moral y metafísico de la voluntad general en Rousseau y incluso el carácter sagrado de la soberanía del pueblo a pesar de su tesis de un giro rousseauniano en la fundación de un nuevo concepto de soberanía del pueblo, cf. Yves Charles Zarka, "Rousseau y la soberanía del pueblo", Derechos y libertades, $\mathrm{n}^{\circ}$ 15, época 2, junio 2006, pp. 47-63.

THÉMATA. Revista de Filosofía, N 49 enero-junio (2014) pp.: 293-315 doi: 10.12795/themata.2014.i49.16 


\section{Referencias bibliográficas:}

Arango, Iván Dario, Críticos y lectores de Rousseau, Medellín, Editorial Universidad de Antioquia, 2006.

Beiner Ronald, Civil Religion, A Dialogue in the History of Political Philosophy, Cambridge University Press, 2011.

Bodin, Jean, Les six livres de la République, Paris, LGF, Paris, 1993.

Coulanges, Fustel de, La cité antique, Paris, Champs-Flammarion, 1996.

Dérathé, Robert, Jean-Jacques Rousseau et la science politique de son temps, Paris, Vrin, 1995.

Garrard, Graeme, "Rousseau, Maistre and the counter-enlightenment", History of Political Thought, Volume 15, n 1, 1994, pp. 97-120.

Jouvenel, Bertrand de, Du pouvoir, Paris, Pluriel, 1998.

Le Bret, Cardin, De la souveraineté du Roy, Paris, J. Quesnel, 1632.

Maistre, Henri de, Joseph de Maistre, Paris, Perrin, 1990.

Maistre, Joseph de, Cinquième lettre d'un royaliste savoisien à ses compatriotes, Revue des études maistriennes, $\mathrm{n}^{\circ} 4,1978$.

Maistre, Joseph de, De la souveraineté du peuple, Paris, PUF, 1992.

Maistre, Joseph de, Du Pape, Oeuvres, T.II, Genève, Slatkine, 1980.

Maistre, Joseph de, Euvres (Pierre Glaudes ed.), Paris, Robert Laffont, "Bouquins ", 2007.

Pranchère, Jean-Yves, "Maistre dans la dialectique des Lumières", Cahiers de l'association internationale des études françaises, $\mathrm{n}^{\circ}$ 525, 2000, pp. 103-115.

Rousseau, Jean-Jacques, Écrits politiques, Euvres complètes, T. III, Bibliothèque de la Pléiade, Paris, Gallimard, 1964.

Schmitt, Carl, Teología política I, Carl Schmitt, Téólogo de la política (Héctor Orestres Aguilar ed.), México, Fondo de Cultura Económica, 2001.

Strauss, Léo, Droit naturel et histoire, Paris, Champs-Flammarion, 2000. Zarka, Yves Charles, "Rousseau y la soberanía del pueblo", Derechos y libertades, $\mathrm{n}^{\mathrm{o}}$ 15, época 2, junio 2006, pp. 47-63. 
